\title{
Histological Study of Adrenal Gland In Case Of Suicidal Deaths
}

\author{
Smita Patra ${ }^{1}$, S. Rath ${ }^{2}$, B.K Dutta ${ }^{3}$ C.Mohapatra ${ }^{4}$,G.B Mishra ${ }^{5}$,R.K.Sahu ${ }^{6}$ \\ P.K . Padhi ${ }^{7}$ R.L. Panda ${ }^{8}$, J.S.Prusty ${ }^{9}$ \\ ${ }^{1}$ Senior Resident, Department of Anatomy, SCB Medical college ,Utkal University ,India . \\ ${ }^{2}$ Professor \& Head, Department of Anatomy, MKCG Medical college, BerhampurUniversity, India \\ ${ }^{3}$ Professor \& Head, Department of Anatomy, VSS Medical college, Sambalpur University, India . \\ ${ }^{4}$ Professor \& Head, Department of Anatomy, SCB Medical college ,Utkal University,India \\ ${ }^{5,6,8,9}$ Associate Professor, Department of Anatomy, MKCG Medical college, BerhampurUniversity , India . \\ ${ }^{7}$ DM, Department of Gastroenterology, SCB Medical College, Utkal University, India .
}

\begin{abstract}
:
Aim \& Objectives: To correlate the Histological adaptive changes in adrenal gland in response to chronic stress since it is a stress responding organ common to both the HPA axis \& Sympathoadrenomedullary axis .

Material \& Methods: Duration of study - Two yrs

Place of study: Dept. of Anatomy, FMT, Pathology of MKCG MC, Berhampur \& SCB MC, Cuttack .

Material for study - Right and Left adrenal .

No. of Suicidal cases -Hundred

No. of Accidental cases (control)-Twenty .

Results: On Histological study it was found that the cells in Zona Glomerulosa showed increased nuclear density. Hypertrophy and hyperplasia of Zona Fasciculata with intracytoplasmic lipid depletion varying from mild to extensive giving rise to parenchymal cord-like arrangement of cells. Sinusoidal prominence in all the three zones including medulla.A normal pattern of Adrenal gland is informative of receipt of sudden violence i.e accident.

Conclusion: The present study concludes and supports the idea that chronic stress as in suicide usually induces adrenal growth which may have implications for forensic people in revealing the cause of unknown deaths.
\end{abstract}

Key words: HPA axis, Stress, Suicide, Sympathoadrenomedullary axis .

\section{Introduction}

Uncertainty and instability are the norm of today's work envioronment. Now-a-days suicidal cases account for more than a million deaths each year. The body's reaction to a stressor is part of our survival mechanism. Under stress, the ACTH is released into circulation by the anterior pituitary. ACTH reaches the adrenal cortex where it stimulates the endocrine cells to secrete the steroid hormone cortisol. The Zona fasciculata of adrenal cortex is rich in lipids which acts as the raw material for the synthesis of $\operatorname{cortisol}^{7}$.ACTH is known to have a proliferative effect on adrenal gland. ${ }^{9}$ It was demonstrated that its chronic liberation induces extracellular signal related kinases (ERKs ) ${ }^{6}, \mathrm{C}$-fos ${ }^{1}, \mathrm{C}$ - jun ${ }^{1}$, activin ${ }^{15}$, spexine, adrenal NPY ${ }^{2}$ etc.to play a crucial role in the cellular proliferation induction. This work has been undertaken to study the histological adaptive changes in adrenal gland in such stressful conditions .

\section{Materials and Methods :}

Duration of Study :2 years ( Aug. 2010- July 2012)

Place of Study :Dept. of Anatomy -SCB MC, Cuttack

Dept. of Pathology - SCB MC , Cuttack.

Dept. of FMT - SCB MC.

Material for study : Right \& Left Adrenal .

Number of suicidal cases : 100

Number of control cases (accidental) : 20

Method of Staining : Routine stain - H\&E

Special staining for lipids - OIL RED O

\subsection{Inclusion Criteria :}

All established cases of suicide with prominent autopsy findings and relevant history . 


\subsection{Exclusion Criteria :}

$>\quad$ Cases with extremes of age groups i.e $<15 \mathrm{yrs}$ and $>60 \mathrm{yrs}$.

$>$ Cases with doubtful and insufficient history.

> Suicidal cases which were brought for Post mortem after $8 \mathrm{hrs}$ of death depending on the environmental temperature and cause of death .

$>$ Pregnant ladies

1.3 Methods for Histological Studies :

$>$ After the gross examintion, several longitudinal cuts were made by a sharp knife.

$>$ Tissue slices of 3 to $5 \mathrm{~mm}$ thick were preserved in $10 \%$ formal saline for $24 \mathrm{hrs} \&$ then the tissues were passed through $30 \%, 50 \%, 70 \%, 90 \% \&$ absolute alcohol , keeping for $12 \mathrm{hrs}$ in each of these .

$>$ Clearing of the tissues were done with Xylene .

$>$ Bathing of the tissues in the Paraffin bath I,II,III .

$>$ Embedding, Sectioning \& Staining with H\& E .

\subsubsection{Lipid Staining :}

$>$ In this process we omit the steps of dehydration and clearing which will remove the lipids.

$>$ We took Cryostat sections of fresh specimens and fixed it with $10 \%$ formal saline for staining with the fat stain i.e Oil Red O .

\subsubsection{Steps for Staining with Oil Red O :}

Fresh specimen from autopsy table was collected, dissected \& cut into $1 \mathrm{~mm}$ size .

$>$ It was smeared with the Cryostat solution \& kept inside the cryostat at the temperature -20 to $-30{ }^{\circ} \mathrm{C}$.

$>$ Frozen sections of 8 to 10 microns were cut \& fixed in $10 \%$ formal saline .

$>$ The stain must be freshly prepared from the stock solution and kept in a closed container.

$>$ The formaline fixed slide is now rinsed with $60 \%$ isopropanol .

$>$ Rinsed slide is stained with freshly prepared Oil Red O working solution for $15 \mathrm{~min}$.

$>$ Then again the slide is rinsed with $60 \%$ isopropanol .

$>$ The slide is then dipped in Alum Haematoxylin for 5-7 dips .

$>$ Then again rinsed with distilled water.

$>$ Finally the slide is mounted in aqueous mountant i.e. glycerine jelly.

\subsubsection{Results :}

$$
\begin{aligned}
& \text { Lipid } \rightarrow \text { Red } \\
& \text { Nuclei } \rightarrow \text { Blue }
\end{aligned}
$$

\subsubsection{Reagent Formulae :}

Oil Red O Stock Stain :

Oil Red O $\rightarrow \quad 0.5 \mathrm{gm}$.

Isopropanol $\rightarrow 100 \mathrm{ml}$.

\subsubsection{Oil Red O Working Solution}

$>\quad 30 \mathrm{ml}$ of the stock solution is diluted with $20 \mathrm{ml}$ of distilled water,allowed to stand for $10 \mathrm{~min}$ \& filtered into a coplin jar \& covered immediately

\section{Observation And Results :}

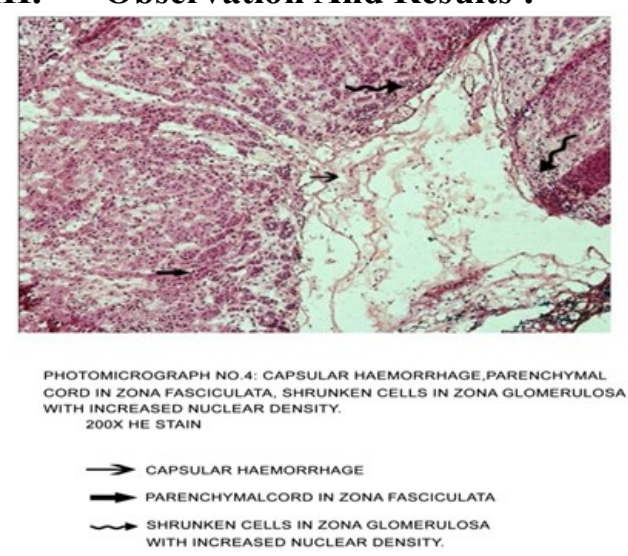


Table-I Histological Findings In Zona Glomerulosa

\begin{tabular}{|l|l|l|}
\hline PARAMETERS & SUICIDAL & CONTROL \\
\hline 1) Cell size & Normal & Normal \\
\hline 2) Nuclear Prominence & Marked(Increased density) & Normal \\
\hline $\begin{array}{l}\text { 3)Sinusoids } \\
\text { 4)Intracytoplasmic lipid } \\
\text { depletion }\end{array}$ & Prominent & Normal \\
\hline $\begin{array}{l}\text { 5)Parenchymal cord like } \\
\text { arrangement of cells }\end{array}$ & Not marked & Not seen \\
\hline
\end{tabular}

PHOTO MICROGRAPH NO : 2 SHOWING CAPSULAR HAEMORRHAGE IN SUICIDAL CASES , $\operatorname{MARKED}(\mathrm{H})$.

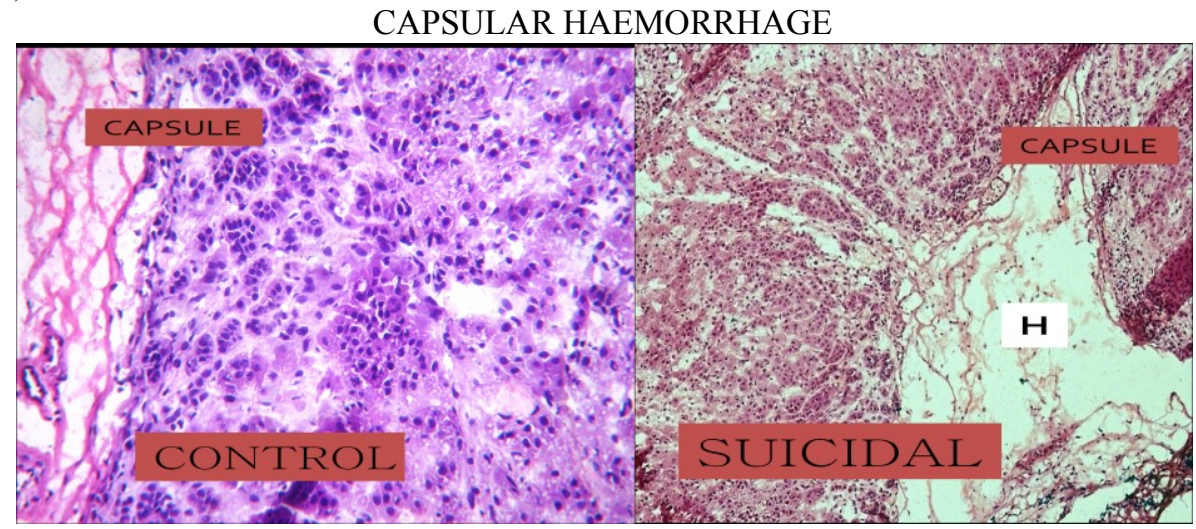

Photomicrograph No : 3 Showing Zonal Extension Of Zona Fasciculata Histological Findings In Suicidal Cases \& Control (H\&E)

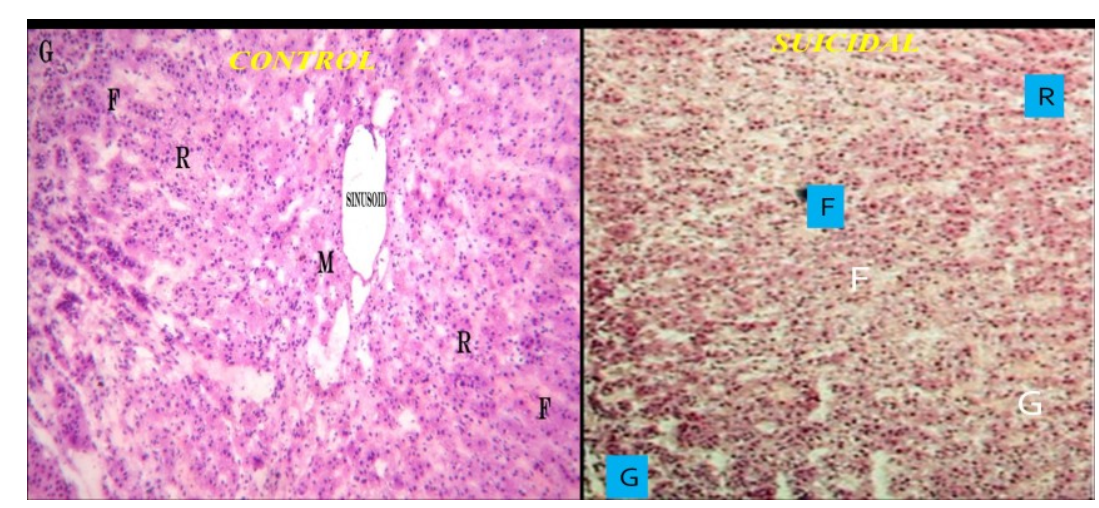


Table -II Histological Findings In Zona Fasciculata :

\begin{tabular}{|c|c|c|}
\hline PARAMETERS & SUICIDAL & CONTROL \\
\hline 1) Extension of ZF & $\begin{array}{l}\text { Hyperplasia \& } \\
\text { Hypertrophy. }\end{array}$ & Normal \\
\hline 2)Cell size & INCREASED & Normal \\
\hline 3)Nuclear Prominence & $\begin{array}{l}\text { Nuclear density greater } \\
\text { in inner zone }\end{array}$ & Normal \\
\hline 4) Sinusoids & Prominent & Normal \\
\hline $\begin{array}{l}\text { 5) Intracytoplasmic lipid } \\
\text { depletion }\end{array}$ & $\begin{array}{l}\text { Varies from mild(+) } \\
\text { patchy to moderate }(++) \\
\text { and finally extensive(+++) }\end{array}$ & Normal \\
\hline $\begin{array}{l}\text { 6)Parenchymal cord like } \\
\text { arrangement }\end{array}$ & INCREASED & $\begin{array}{l}\text { No such arrangement } \\
\text { seen }\end{array}$ \\
\hline
\end{tabular}

Photomicrograph No : 4 Showing Zonal Extension In Zona Fasciculata In Suicidal Cases Zonal Extention

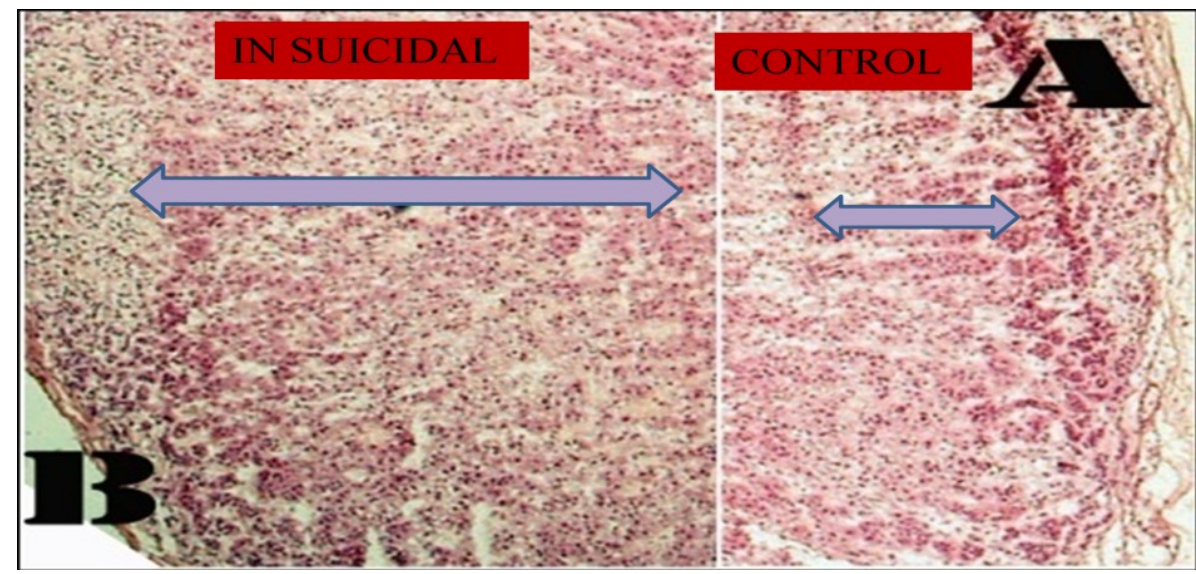

Photomicrograph No : 5 Showing degrees of lipid depletion in Zona Fasciculata ( Suicidal cases )

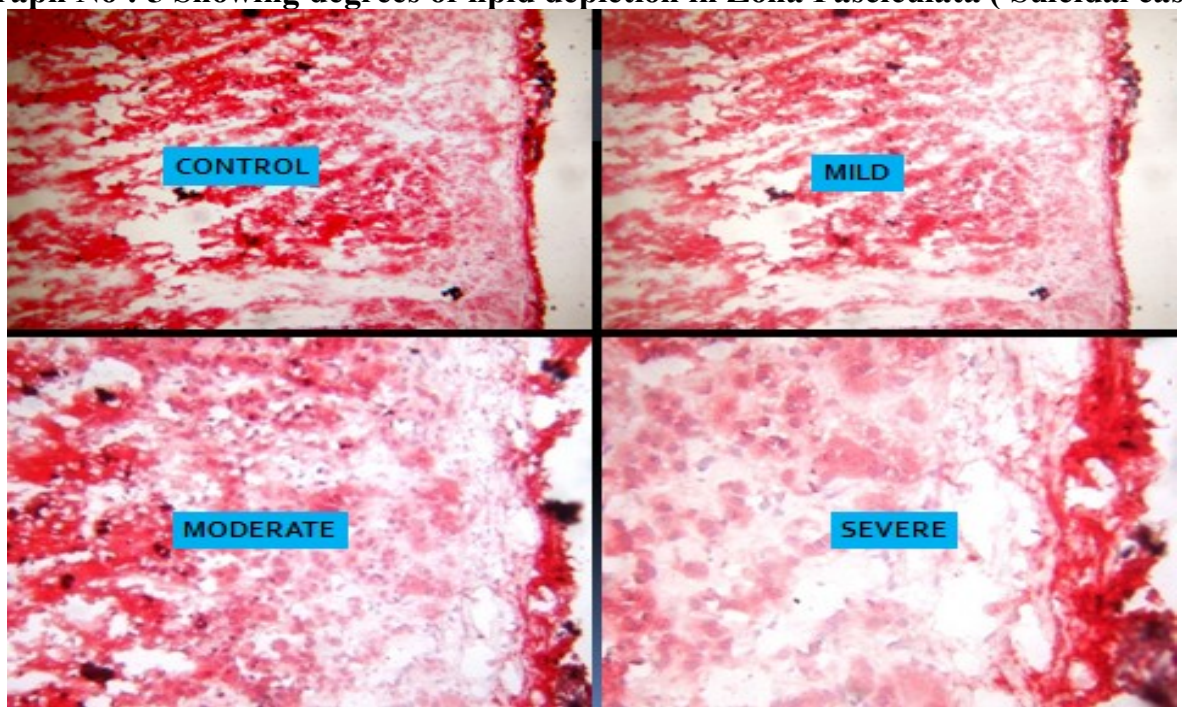


Photomicrograph No : 6 Showing Sinusoidal Prominence In Suicidal Cases

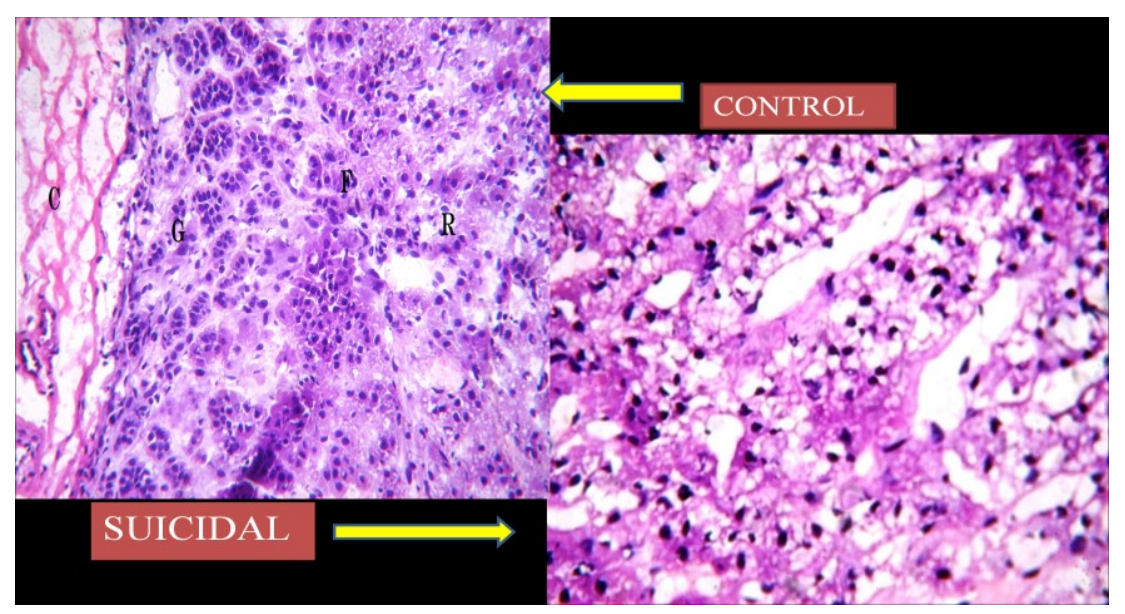

Table - III Showing Histilogical Findings In Zona Reticularis

\begin{tabular}{l}
\begin{tabular}{l|l|l|}
\hline PARAMETERS & SUICIDAL & CONTROL \\
\hline $\begin{array}{l}\text { 1)Extension of zona } \\
\text { reticularis }\end{array}$ & Slight increase & normal \\
\hline $\begin{array}{l}\text { 2) Cell size } \\
\text { 3)Nuclearprominence }\end{array}$ & Not marked & normal \\
\hline 4)Sinusoids & Prominent & normal \\
\hline & & Normal \\
\hline
\end{tabular} \\
\hline
\end{tabular}

Photomicrograph No : 7 Sinusoidal Prominence In Zona Reticularis

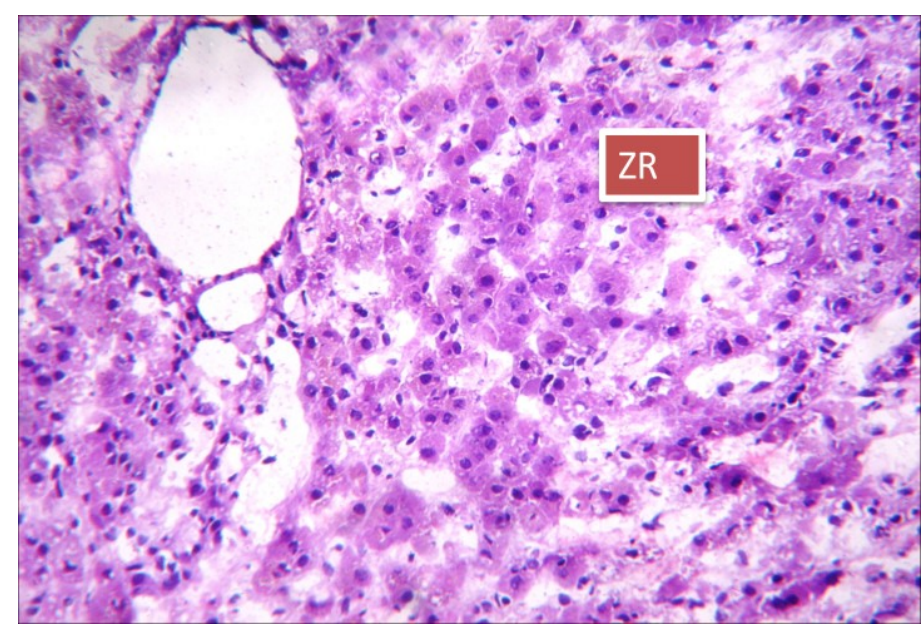


Table - IV Histological Findings In Adrenal Medulla :

\begin{tabular}{|l|l|l|}
\hline PARAMETERS & SUICIDAL & CONTROL \\
\hline 1)Extension of medulla & Increased & Normal \\
\hline 2) Cell size & Increased & Normal \\
\hline 3)NuclearProminence & Normal & Normal \\
\hline 4)Sinusoids & & Normal \\
\hline
\end{tabular}

Photomicrograph No -8

\section{Prominence Of Sinusoids In Adrenal Medulla}

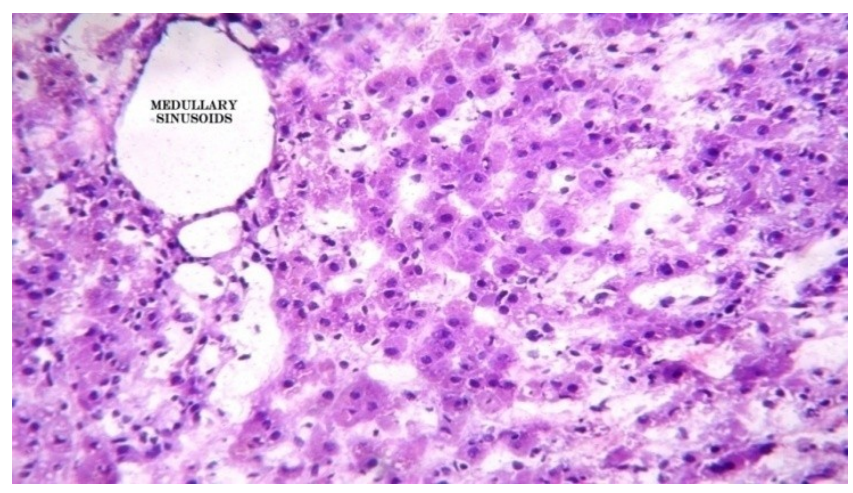

IV. Discussion :

Lipid accumulation in cells denote hypoactivity \& lipid depletion indicates hyperactivity as seen in chronic stress. ${ }^{12}$ ( Sayers et al, 1950).

In the present study Lipid depletion is seen in $\mathrm{ZF}$ in $90 \%$ cases which corroborates with the findings of Howe EE (2000), ${ }^{7}$ Kare M (1969), ${ }^{8}$ Willenberg H.S. et al \& Rich A.R.et al ( 1998).

It is found that there is a hypertrophy in the inner region \& hyperplasia in the outer region of $\mathrm{ZF}$ which is correlated with the findings of Yvonne M,Ulrich Lei et al (2006). ${ }^{16}$

In $70 \%$ of the cases there is presence of prominent sinusoids which reflects the further vascular demand for the increased endocrine activities of adrenal in adaptation to new challenges to stress which corroborates with the findings of Howe EE (2000) ${ }^{7}$.

Increased parenchymal cord like formation was probably due to lipid depletion ? BaccaroRB, Mendonce PO, Torres TE et al, 2007 found a growth factor FGF responsible for adrenocortical growth in response to stress.

According to Viard et al. (1994), it was observed that ACTH blocks progression of adrenocortical cells in G1 phase and inhibits DNA synthesis in S-phase, even in the presence of growth factors. After this inhibiting effect, ACTH induces expression of genes associated with cell cycle progression such as C-fos and C-jun. ${ }^{17}$

Bicknell et al (2001) stated that peptides from the N-terminal region of ACTH precursor causes hypertrophy and hyperplasia. $^{3}$ 
Spencer SJ et al (1992) stated that transforming growth factor $\beta$ and activin play role in hypertrophy and hyperplasia. ${ }^{15}$

Peptide NPY ${ }^{2}$ responsible for adrenal growth as stated by Bernet et al (1998).

Spexime ${ }^{11}$ a polypeptide has a strong inhibitory effect on the proliferative activity of adrenal cortex in stressful condition (Rucinski et al., 2010).

\section{Conclusion}

The present study concludes and supports the idea that chronic stress as in suicide usually induces adrenal growth (evidenced by zonal extention), lipid depletion \& sinusoidal prominence which may have implications for forensic people in revealing the cause of unknown deaths .

\section{References}

[1]. Baccaro, R. B; Mendnca, P. O.; Torres, T. E. \&Lotfi, C. F. Immunohistochemical Jun/Fos protein localization and DNA synthesis in rat adrenal cortex after treatment with ACTH or FGF2. Cell Tissue Res., 328( vol 1 ) 7-18, 2007.

[2]. Bernet, F,; Dedieu, J. F,; Laborie, C.; Montel, V. \&Dupouy, J. P. Circulating Neuropeptide Y (NPY) and catecholamines in rat under resting and stress conditions. Arguments for extra- adrenal origin of NPY, adrenal \& extra- adrenal sources of catecholamines. Neurosci. Lett., 250 (1); 45-8, 1998.

[3]. Bicknell AB, Lomthaisong K, Woods RJ, ET AL, Characterization of a serine protease that cleaves pro-gamma-melanotropin at the adrenal to stimulate growth. Cell. 2001; 105:903-912.

[4]. Bland, M. L.; Desclozeaux, M. \& Ingraham, H. A. Tissue growth and remodeling of the embryonic and adult adrenal gland. Ann. N. Y. Acad. Sci. 995:59-72, 2003.

[5]. Collins, M. K.; Perkins, G. R,; Rodriguez -Tarduchy, G,; Nieto, M. A. \& Lopez -Rivas, A. Growth factors as survival factors : regulation of apoptosis. Bioessays, 16(2): 133-38, 1994

[6]. Ferreira, J. G.; Cruz, C. D.; Neves, D \&Pignatelli, D. Increased extracellular signal regulated kinases phosphorylation in the adrenal gland in response to chronic ACTH treatment. J. Endocr. 192(3) : 647-58, 2007.

[7]. Howe $\mathrm{EE}^{1}$, Wronski TJ, Halloran BP, Miller SC. Histologic changes in the adrenal cortex from young rats following spaceflight.Aviat Space Environ. Med.Histologoc 2000 Oct;71(10)1039-44

[8]. Kare M. The adrenal weight of mice with spontaneous adrenocortical lipid depletion. Acta. Path. Microbio. Scandinav; 75 : $37-50$. 1969.

[9]. Kobayashi, H.; Kambe, F.; Imai, T.; Hibi, Y.; Kikumori, T.; Ohmori, S.; Nakao, A. \&Seo, H. Differential expression of cyclin dependent kinase inhibitors, p 27 Kip 1 and p 57 Kip2, by corticotrophin in rat adrenal cortex. J. Endocr. 189(3):671 -9, 2006.

[10]. Nussdorfer, G. G. Cytophysiology of the adrenal cortex. Int. Rev. Cytol., $98: 1-405,1986$. Nussdorfer, G. G. Cytophysiology of the adrenal cortex. Int. Rev. Cytol., $98: 1-405,1986$.

[11]. Rucinski, M,;Porzionato, A,; Ziolkowaska, a,; Szyszka, m.; Macchi, V.; DeCaro, R. \&Malendowicz, LK. Expression of the Spexine gene in the rat adrenal gland and evidences suggesting that spexine inhibits adrenocortical cell proliferation. Peptides, 31(4) : 67682,2010 .

[12]. Sayers, G., (1950) Adrenal cortex and Homeostasis Physiological Reviews, Vol. 30, July, 1950, pp. 276.

[13]. Selye H. Stress and Disease, Sc. Oct. 7, 1955, 122: 625-631.

[14]. Selye H. The stress of life. New York : McGraw Hill, 1956.

[15]. Spencer SJ, Rabinovici, J. Mesiano S, Goldsmith PC, Jaffe RB. Activin and inhibin in the human adrenal gland. Regulation and diffenetial effects in fetal

[16]. and adult cells, J. Clin Invest. 1992; 90: 142-149.

[17]. Ulrich-lai, Y. M.; Figueiredo, H. F.; Ostrander, M. M.; Choi, D. C.; Engeland, W. C. \& Herman, J. P. Chronic stress induces adrenal hyperplasia and hypertrophy in a subregion -specific manner. Am. J. Physiol. Endocrinol. Metab., 291(5):E965-73.

[18]. Viard, I.; Penhoat, A.; Ouali, R.; Langlois, D.; Bégeot, M. \&Saez, J. M. Peptide hormone and growth factor regulation of nuclear proto-oncogenes and specific functions in adrenal cells. J. Steroid. Biochem. Mol. Biol., 50(5-6):219-24, 1994.

[19]. Vinson, G. P. Adrenocortical zonation and ACTH. Microsc. Res. Tech., 61(3):227-39, 2003. 